\title{
Emergency department use by patients with end-stage renal disease in the United States
}

Ningyuan Wang ${ }^{1 \dagger}$, Jiao Pei ${ }^{2,3+}$, Hui Fan ${ }^{4}$, Yaseen Ali $^{1}$, Anna Prushinskaya ${ }^{5}$, Jian Zhao ${ }^{6,7,8}$ and Xingyu Zhang ${ }^{5^{*}}$ (D)

\begin{abstract}
Background: We sought to describe the national characteristics of ED visits by patients with end-stage renal disease (ESRD) in the United States in order to improve the emergency treatment and screening of ESRD patients.

Methods: We analyzed data from 2014 to 2016 ED visits provided by the National Hospital Ambulatory Medical Care Survey. We sampled adult (age $\geq 18$ years) ED patients with ESRD. By proportion or means of weighted sample variables, we quantified annual ED visits by patients with ESRD. We investigated demographics, ED resource utilization, clinical characteristics, and disposition of patients with ESRD and compared these to those of patients without ESRD. Logistic regression models were used to estimate the association between these characteristics and ESRD ED visits.

Results: Approximately 722,692 (7.78\%) out of 92,899,685 annual ED visits represented ESRD patients. Males were more likely to be ESRD patients than females (aOR: 1.34; 95\% Cl: 1.09-1.66). Compare to whites, non-Hispanic Blacks were 2.55 times more likely to have ESRD (aOR: $2.55 ; 95 \%$ Cl: 1.97-3.30), and Hispanics were 2.68 times more likely to have ESRD (95\% Cl: 1.95-3.69). ED patients with ESRD were more likely to be admitted to the hospital (aOR: 2.70; 95\% Cl: 2.13-3.41) and intensive care unit (ICU) (aOR: 2.21; 95\% Cl: 1.45-3.38) than patients without ESRD. ED patients with ESRD were more likely to receive blood tests and get radiology tests.

Conclusion: We described the unique demographic, socioeconomic, and clinical characteristics of ED patients with ESRD, using the most comprehensive, nationally representative study to date. These patients' higher hospital and ICU admission rates indicate that patients with ESRD require a higher level of emergency care.
\end{abstract}

Keywords: End-stage renal disease, Emergency medicine, National characteristics, Resource utilization

\section{Background}

Kidney diseases are the ninth leading cause of death in the United States. Fifteen percent of U.S. adults, about 37 million people, were estimated to have chronic kidney disease (CKD) in 2019 [1]. End-stage renal disease (ESRD), the final stage of CKD, has emerged as one of the most important public health

\footnotetext{
* Correspondence: zhangxyu@umich.edu

${ }^{\dagger}$ Ningyuan Wang and Jiao Pei contributed equally to this work.

${ }^{5}$ Department of Systems, Populations, and Leadership, University of Michigan School of Nursing, Ann Arbor, Ml 48109, USA

Full list of author information is available at the end of the article
}

concerns in the United States. In 2016, approximately 125,000 people in the U.S. started treatment for endstage kidney disease, and over 726,000 were on dialysis or living with a kidney transplant [1]. The total Medicare expenditure (excluding prescription drugs) for patients with ESRD or kidney failure reached \$35 billion, accounting for about $7 \%$ of the Medicare paid claims costs [2]. At the end of 2017, 746,557 ESRD cases were reported in the U.S., which represents an increase of $2.6 \%$ from 2016 and an increase of $91.1 \%$ from 2000 [3]. The prevalence of ESRD in the U.S. is

C C The Author(s). 2021 Open Access This article is licensed under a Creative Commons Attribution 4.0 International License, which permits use, sharing, adaptation, distribution and reproduction in any medium or format, as long as you give appropriate credit to the original author(s) and the source, provide a link to the Creative Commons licence, and indicate if changes were made. The images or other third party material in this article are included in the article's Creative Commons licence, unless indicated otherwise in a credit line to the material. If material is not included in the article's Creative Commons licence and your intended use is not permitted by statutory regulation or exceeds the permitted use, you will need to obtain permission directly from the copyright holder. To view a copy of this licence, visit http://creativecommons.org/licenses/by/4.0/ The Creative Commons Public Domain Dedication waiver (http://creativecommons.org/publicdomain/zero/1.0/) applies to the data made available in this article, unless otherwise stated in a credit line to the data. 
expected to continue to increase through the year 2030 [4].

Patients with ESRD are often frail and comorbid which puts them at high risk for emergency department (ED) visits and hospitalization. Nearly two-thirds of patients with ESRD are admitted to the hospital in the year prior to initiating renal replacement therapy [5], and the rehospitalization rate for patients with ESRD is more than $30 \%$ higher than the rate of rehospitalization for other patients [6, 7]. The ED plays an important role for ESRD patients that seek urgent care. Therefore, identifying the characteristics of ESRD patients who visit the ED would be beneficial and can help to optimize ED resource utilization and perhaps alleviate the burden currently placed on the ED by these patients. Previous studies have documented high hospital resource use among patients with ESRD $[8,9]$; however, literature focused on ED utilization amongst this population is sparse, and specifically literature that relates ESRD visits proportionally to other ED visits is limited [10]. As such, in the present study, we aim to examine the national characteristics of ED utilization among patients with ESRD and their corresponding usage proportion in the U.S. from 2014 to 2016.

\section{Methods}

\section{Study population}

The study population consists of all adult patients (age $\geq$ 18 years) $(N=42,832$; Weighted $N=278,699,057)$ in the National Hospital Ambulatory Medical Care Survey Emergency Department Subfile (NHAMCS-ED) from 2014 to 2016 [11]. NHAMCS-ED is a nationally representative, multistage, stratified probability sample of ED visits in the United States administered by the National Center for Health Statistics, a branch of the Centers for Disease Control and Prevention. The NHAMCS-ED sample is collected from approximately 300 hospitalbased EDs per year, which are randomly selected from approximately 1900 geographic areas in all 50 states. The survey uses a standardized data collection form to gather detailed information from approximately $100 \mathrm{pa}-$ tients per hospital-based ED.

\section{Study variables}

The primary outcome for the study is the patient ESRD status noted as "ESRD status." In NHAMCS, ESRD status "includes all types of end-stage renal disease and chronic kidney failure due to diabetes or hypertension" [12].

The secondary outcomes include the emergency severity index (ESI) score (a five-level ED triage algorithm providing clinically relevant stratification of patients into five groups from 1 (most urgent) to 5 (least urgent) on the basis of acuity and resource needs); hospital admission; intensive care unit (ICU) admission; blood tests; imaging (including X-ray, CT, ultrasound, MRI); procedures (BiPAP/CPAP; bladder catheter; cast, splint, wrap; central line; IV fluids; CPR; endotracheal intubation; incision \& drainage (I\&D); IV fluids; lumbar puncture (LP); nebulizer therapy; pelvic exam; skin adhesives; suturing/staples; Other); whether the patient left before triage/treatment; length of stay; and whether the patient died in the ED/hospital.

The covariates examined include demographic characteristics (e.g., patient age, sex, race/ethnicity, region, residence type); time, date, and mode of arrival; insurance status; triage vital signs (including temperature, pain scale, blood pressure, etc.), and reasons for ED visit.

\section{Statistical analysis}

Population characteristics between ESRD and non-ESRD groups were described and compared using chi-square or $t$ test. We used logistic regression to examine the association between the primary outcome (ED patients with ESRD versus ED patients without ESRD) and the covariates. We also used logistic regression to test the association between ESRD status and secondary outcomes by adjusting for other covariates. Missing values were imputed with the median of each covariate when establishing the multivariable logistic regression. SAS (version 9.4) was used for analyses, with $\alpha=0.05$ set as the statistical significance threshold. This study was determined to be exempt by the institutional review board.

\section{Results}

Between 2014 and 2016, there were 278,699,057 total adult ED visits in the United States. Patients with ESRD made up approximately $2,168,075$ (7.78\% or 722,692 annually) of these visits. In addition, the proportion of ED visits by patients with ESRD increased between 2014 to 2016. Basic characteristics are described in Table 1. The proportion of ED visits by patients with ESRD varied by US census region: Northwest, 13.4\%; Midwest, 19.8\%; South, 45.6\%; and West, 21.2\% $(p<0.01)$. ESRD patients and non-ESRD patients differed significantly in age and race $(p<0.001)$.

Tables 2, 3, and 4 describe the proportions and associations of ESI, hospital admission, ICU admission, and medical resource utilization for ESRD and non-ESRD patients. The hospital admission rate among ED patients was 2.70 times higher for patients with ESRD (95\% CI: 2.13-3.41); ESRD patients were also 4.72 times more likely to receive immediate or emergent vs. semi- or non-urgent ESI scores compared to patients without ESRD (95\% CI: 3.00-7.41). The ICU admission rate was 2.21 times higher for patients with ESRD (95\% CI: 1.453.38). ED patients with ESRD were 2.54 times more 
Table 1 Baseline characteristics of patients presenting to the ED, stratified by ESRD, NHAMCS 2014-2016

\begin{tabular}{|c|c|c|c|c|c|c|c|}
\hline & \multicolumn{3}{|c|}{ Unweighted sample } & \multicolumn{3}{|c|}{ Weighted sample } & \multirow[t]{2}{*}{$p$ value } \\
\hline & All & No ESRD & ESRD & All & No ESRD & ESRD & \\
\hline & 42,832 & 42,465 & 367 & $278,699,057$ & $276,530,981$ & $2,168,075$ & \\
\hline Male & $\begin{array}{l}18,469 \\
(43.1)\end{array}$ & $\begin{array}{l}18,283 \\
(43.1)\end{array}$ & $\begin{array}{l}186 \\
(50.7)\end{array}$ & $\begin{array}{l}119,751,766 \\
(43.0)\end{array}$ & $\begin{array}{l}118,611,308 \\
(42.9)\end{array}$ & $\begin{array}{l}1,140,459 \\
(52.6)\end{array}$ & 0.0033 \\
\hline \multicolumn{8}{|l|}{ Age } \\
\hline $18-39$ & $\begin{array}{l}17,912 \\
(41.8)\end{array}$ & $\begin{array}{l}17,862 \\
(42.1)\end{array}$ & $50(13.6)$ & $\begin{array}{l}118,068,691 \\
(42.4)\end{array}$ & $\begin{array}{l}117,768,064 \\
(42.6)\end{array}$ & $300,627(13.9)$ & $<0.001$ \\
\hline $40-49$ & $6662(15.6)$ & 6629 (15.6) & $33(9.0)$ & $43,185,040(15.5)$ & $43,021,286(15.6)$ & 163,755 (7.6) & \\
\hline $50-59$ & $6707(15.7)$ & $6638(15.6)$ & $69(18.8)$ & $42,679,091(15.3)$ & $42,215,775(15.3)$ & $463,316(21.4)$ & \\
\hline $60-74$ & $6678(15.6)$ & $6542(15.4)$ & $\begin{array}{l}136 \\
(37.1)\end{array}$ & $43,420,164(15.6)$ & $42,634,581(15.4)$ & $785,583(36.2)$ & \\
\hline$>=75$ & $4873(11.4)$ & $4794(11.3)$ & 79 (21.5) & $31,346,071(11.2)$ & $30,891,277(11.2)$ & $454,793(21.0)$ & \\
\hline \multicolumn{8}{|l|}{ Race/ethnicity } \\
\hline White & $\begin{array}{l}27,251 \\
(63.6)\end{array}$ & $\begin{array}{l}27,079 \\
(63.8)\end{array}$ & $\begin{array}{l}172 \\
(46.9)\end{array}$ & $\begin{array}{l}175,775,546 \\
(63.1)\end{array}$ & $\begin{array}{l}174,659,617 \\
(63.2)\end{array}$ & $\begin{array}{l}1,115,929 \\
(51.5)\end{array}$ & $<0.001$ \\
\hline Black & $9207(21.5)$ & $9092(21.4)$ & $\begin{array}{l}115 \\
(31.3)\end{array}$ & $62,663,628(22.5)$ & $62,051,038(22.4)$ & $612,590(28.3)$ & \\
\hline Hispanic & $5152(12.0)$ & $5094(12.0)$ & $58(15.8)$ & $33,391,671(12.0)$ & $33,055,349(12.0)$ & $336,322(15.5)$ & \\
\hline Asian & $804(1.9)$ & 793 (1.9) & $11(3.0)$ & $4,392,213$ (1.6) & $4,349,798$ (1.6) & $42,415(2.0)$ & \\
\hline Other & $418(1.0)$ & $407(1.0)$ & $11(3.0)$ & $2,475,999(0.9)$ & $2,415,180(0.9)$ & $60,819(2.8)$ & \\
\hline \multicolumn{8}{|l|}{ Residence type } \\
\hline Private residence & $\begin{array}{l}39,819 \\
(95.1)\end{array}$ & $\begin{array}{l}39,498 \\
(95.1)\end{array}$ & $\begin{array}{l}321 \\
(89.7)\end{array}$ & $\begin{array}{l}258,354,513 \\
(95.3)\end{array}$ & $\begin{array}{l}256,528,244 \\
(95.3)\end{array}$ & $\begin{array}{l}1,826,269 \\
(85.6)\end{array}$ & $<0.001$ \\
\hline Nursing home & $885(2.1)$ & $856(2.1)$ & $29(8.1)$ & $5,875,161(2.2)$ & $5,632,038(2.1)$ & $243,123(11.4)$ & \\
\hline Homeless & $534(1.3)$ & $534(1.3)$ & $0(0.0)$ & $2,480,109(0.9)$ & $2,480,109(0.9)$ & $0(0.0)$ & \\
\hline Other & $651(1.6)$ & $643(1.5)$ & $8(2.2)$ & $4,501,686(1.7)$ & $4,437,115$ (1.6) & $64,571(3.0)$ & \\
\hline \multicolumn{8}{|l|}{ Insurance type } \\
\hline Private insurance & $\begin{array}{l}12,446 \\
(30.8)\end{array}$ & $\begin{array}{l}12,411 \\
(31.0)\end{array}$ & $35(9.8)$ & $79,443,111(30.5)$ & $79,249,592(30.7)$ & $193,519(9.1)$ & $<0.001$ \\
\hline Medicare & $\begin{array}{l}10,517 \\
(26.0)\end{array}$ & $\begin{array}{l}10,278 \\
(25.7)\end{array}$ & $\begin{array}{l}239 \\
(66.8)\end{array}$ & $66,956,323(25.7)$ & $65,443,229(25.3)$ & $\begin{array}{l}1,513,093 \\
(71.2)\end{array}$ & \\
\hline Medicaid or CHIP & $\begin{array}{l}11,148 \\
(27.6)\end{array}$ & $\begin{array}{l}11,080 \\
(27.7)\end{array}$ & $68(19.0)$ & $71,529,605(27.5)$ & $71,197,275$ (27.6) & $332,331(15.6)$ & \\
\hline Uninsured & $4886(12.1)$ & $4876(12.2)$ & $10(2.8)$ & $33,248,283(12.8)$ & $33,203,302(12.8)$ & $44,981(2.1)$ & \\
\hline Other & $1406(3.5)$ & $1400(3.5)$ & $6(1.7)$ & $9,371,908(3.6)$ & $9,329,217(3.6)$ & $42,691(2.0)$ & \\
\hline Arrive by ambulance & $7729(18.5)$ & $7600(18.4)$ & $\begin{array}{l}129 \\
(35.8)\end{array}$ & $49,769,047(18.3)$ & $48,948,071(18.2)$ & 820,977 (38.3) & $<0.001$ \\
\hline Seen within last $72 \mathrm{~h}$ & $1914(4.9)$ & $1898(4.9)$ & $16(4.8)$ & $11,953,039(4.8)$ & $11,874,648(4.8)$ & $78,391(4.1)$ & 0.8948 \\
\hline \multicolumn{8}{|l|}{ Pain level } \\
\hline No pain & $7711(24.4)$ & $7610(24.2)$ & $\begin{array}{l}101 \\
(39.8)\end{array}$ & $46,478,004(23.1)$ & $45,940,926(23.0)$ & $537,078(37.6)$ & $<0.001$ \\
\hline Mild & $2916(9.2)$ & $2903(9.2)$ & $13(5.1)$ & $18,235,636(9.1)$ & $18,178,674(9.1)$ & $56,962(4.0)$ & \\
\hline Moderate & $9430(29.8)$ & $9363(29.8)$ & $67(26.4)$ & $60,509,861(30.1)$ & $60,090,165(30.1)$ & $419,696(29.4)$ & \\
\hline Severe & $\begin{array}{l}11,602 \\
(36.6)\end{array}$ & $\begin{array}{l}11,529 \\
(36.7)\end{array}$ & $73(28.7)$ & $75,762,102(37.7)$ & $75,347,113(37.8)$ & $414,989(29.0)$ & \\
\hline
\end{tabular}


Table 1 Baseline characteristics of patients presenting to the ED, stratified by ESRD, NHAMCS 2014-2016 (Continued)

\begin{tabular}{|c|c|c|c|c|c|c|c|}
\hline & \multicolumn{3}{|c|}{ Unweighted sample } & \multicolumn{3}{|l|}{ Weighted sample } & \multirow[t]{2}{*}{$p$ value } \\
\hline & All & No ESRD & ESRD & All & No ESRD & ESRD & \\
\hline \multicolumn{8}{|l|}{ Temperature } \\
\hline $36^{\circ} \mathrm{C}-38^{\circ} \mathrm{C}$ & $\begin{array}{l}38,083 \\
(94.6)\end{array}$ & $\begin{array}{l}37,784 \\
(94.7)\end{array}$ & $\begin{array}{l}299 \\
(90.6)\end{array}$ & $\begin{array}{l}249,171,894 \\
(95.1)\end{array}$ & $\begin{array}{l}247,406,971 \\
(95.1)\end{array}$ & $\begin{array}{l}1,764,922 \\
(92.5)\end{array}$ & $<0.001$ \\
\hline$<=36^{\circ} \mathrm{C}$ & $1522(3.8)$ & $1504(3.8)$ & $18(5.5)$ & $9,089,224(3.5)$ & $9,001,036(3.5)$ & $88,187(4.6)$ & \\
\hline$>38^{\circ} \mathrm{C}$ & $635(1.6)$ & $622(1.6)$ & $13(3.9)$ & $3,863,922(1.5)$ & $3,808,689(1.5)$ & $55,233(2.9)$ & \\
\hline \multicolumn{8}{|l|}{ Heart Rate } \\
\hline$<=90$ & $\begin{array}{l}28,489 \\
(66.5)\end{array}$ & $\begin{array}{l}28,242 \\
(66.5)\end{array}$ & $\begin{array}{l}247 \\
(67.3)\end{array}$ & $\begin{array}{l}184,822,552 \\
(66.3)\end{array}$ & $\begin{array}{l}183,317,566 \\
(66.3)\end{array}$ & $1504,986(69.4)$ & 0.5082 \\
\hline $90-100$ & 7169 (16.7) & 7109 (16.7) & $60(16.3)$ & 46,314,663 (16.6) & 45,999,951 (16.6) & $314,712(14.5)$ & \\
\hline $100-110$ & $3906(9.1)$ & $3876(9.1)$ & $30(8.2)$ & $25,427,295(9.1)$ & $25,268,229(9.1)$ & $159,066(7.3)$ & \\
\hline $110-120$ & 1988 (4.6) & $1974(4.6)$ & $14(3.8)$ & $13,118,183(4.7)$ & $13,062,583(4.7)$ & $55,600(2.6)$ & \\
\hline$>120$ & $1280(3.0)$ & $1264(3.0)$ & $16(4.4)$ & $9,016,363(3.2)$ & $8,882,652(3.2)$ & $133,711(6.2)$ & \\
\hline \multicolumn{8}{|l|}{ DBP } \\
\hline $60-80$ & $\begin{array}{l}19,358 \\
(45.2)\end{array}$ & $\begin{array}{l}19,213 \\
(45.2)\end{array}$ & $\begin{array}{l}145 \\
(39.5)\end{array}$ & $\begin{array}{l}125,677,278 \\
(45.1)\end{array}$ & $\begin{array}{l}124,830,342 \\
(45.1)\end{array}$ & 846,937 (39.1) & $<0.001$ \\
\hline$<60$ & $4312(10.1)$ & $4233(10.0)$ & $79(21.5)$ & 26,198,088 (9.4) & $25,714,760(9.3)$ & $483,328(22.3)$ & \\
\hline$>80$ & $\begin{array}{l}19,162 \\
(44.7)\end{array}$ & $\begin{array}{l}19,019 \\
(44.8)\end{array}$ & $\begin{array}{l}143 \\
(39.0)\end{array}$ & $\begin{array}{l}126,823,690 \\
(45.5)\end{array}$ & $\begin{array}{l}125,985,881 \\
(45.6)\end{array}$ & 837,810 (38.6) & \\
\hline \multicolumn{8}{|l|}{ SBP } \\
\hline $80-120$ & $9773(22.8)$ & $9687(22.8)$ & $86(23.4)$ & $61,351,488(22.0)$ & $60,857,637(22.0)$ & $493,851(22.8)$ & 0.4365 \\
\hline$<80$ & $1588(3.7)$ & $1570(3.7)$ & $18(4.9)$ & $9,419,022(3.4)$ & $9,310,953(3.4)$ & $108,068(5.0)$ & \\
\hline$>120$ & $\begin{array}{l}31,471 \\
(73.5)\end{array}$ & $\begin{array}{l}31,208 \\
(73.5)\end{array}$ & $\begin{array}{l}263 \\
(71.7)\end{array}$ & $\begin{array}{l}207,928,547 \\
(74.6)\end{array}$ & $\begin{array}{l}206,362,392 \\
(74.6)\end{array}$ & $\begin{array}{l}1,566,155 \\
(72.2)\end{array}$ & \\
\hline \multicolumn{8}{|l|}{ Census Region } \\
\hline Northeast & 7176 (16.8) & 7140 (16.8) & $36(9.8)$ & 43,967,048 (15.8) & $43,675,459(15.8)$ & $291,588(13.4)$ & 0.0004 \\
\hline Midwest & $\begin{array}{l}10,893 \\
(25.4)\end{array}$ & $\begin{array}{l}10,807 \\
(25.4)\end{array}$ & $86(23.4)$ & $74,304,118(26.7)$ & $73,875,207(26.7)$ & $428,911(19.8)$ & \\
\hline South & $\begin{array}{l}15,430 \\
(36.0)\end{array}$ & $\begin{array}{l}15,268 \\
(36.0)\end{array}$ & $\begin{array}{l}162 \\
(44.1)\end{array}$ & $\begin{array}{l}105,760,507 \\
(37.9)\end{array}$ & $\begin{array}{l}104,771,742 \\
(37.9)\end{array}$ & $988,765(45.6)$ & \\
\hline West & $9333(21.8)$ & $9250(21.8)$ & $83(22.6)$ & $54,667,385(19.6)$ & $54,208,574(19.6)$ & $458,811(21.2)$ & \\
\hline \multicolumn{8}{|l|}{ This visit is related to } \\
\hline Injury/trauma & $\begin{array}{l}12,286 \\
(30.1)\end{array}$ & $\begin{array}{l}12,248 \\
(30.3)\end{array}$ & $38(11.0)$ & $78,178,483(29.5)$ & $77,992,283(29.6)$ & $186,200(9.1)$ & $<0.001$ \\
\hline Overdose/poisoning & $499(1.2)$ & $498(1.2)$ & $1(0.3)$ & $3,358,380(1.3)$ & $3,349,593(1.3)$ & $8787(0.4)$ & \\
\hline $\begin{array}{l}\text { Adverse effect of medical/surgical } \\
\text { treatment }\end{array}$ & $1099(2.7)$ & $1063(2.6)$ & $36(10.4)$ & $7,170,683(2.7)$ & $6,961,906(2.6)$ & $208,777(10.2)$ & \\
\hline Visit not related to any above & $\begin{array}{l}26,692 \\
(65.4)\end{array}$ & $\begin{array}{l}26,424 \\
(65.3)\end{array}$ & $\begin{array}{l}268 \\
(77.7)\end{array}$ & $\begin{array}{l}174,903,611 \\
(66.0)\end{array}$ & $\begin{array}{l}173,277,339 \\
(65.9)\end{array}$ & $\begin{array}{l}1,626,272 \\
(79.4)\end{array}$ & \\
\hline Questionable injury status & $214(0.5)$ & $212(0.5)$ & $2(0.6)$ & $1,546,669(0.6)$ & $1,528,096(0.6)$ & $18,573(0.9)$ & \\
\hline
\end{tabular}

likely to receive blood tests (95\% CI: $1.89-3.40)$ as well as more likely to utilize X-rays (95\% CI: $1.43-2.24)$.

The associations between ED patients' demographic, socioeconomic, and clinical characteristics and their ESRD status are outlined in Supplement Table 1. Male ED patients were $34 \%$ more likely to have ESRD than were female patients (aOR: 1.34; 95\% CI: 1.09-1.66). Among ED patients, non-
Hispanic Blacks were 2.55 times more likely than whites to have ESRD (aOR: 2.55; 95\% CI: 1.97-3.30); Hispanics were 2.68 times more likely than whites to have ESRD (95\% CI: 1.95-3.69); and Asians were 2.90 times more likely than whites to have ESRD (95\% CI: 1.53-5.50).

Compared to ED patients inhabiting a private residence, those who were living in nursing homes were 
Table 2 Selected reason for visit and emergency department diagnosis among ED patients with ESRD, NHAMCS 2014-2016

\begin{tabular}{|c|c|c|c|c|c|c|}
\hline & \multicolumn{3}{|c|}{ Unweighted sample } & \multicolumn{3}{|c|}{ Weighted sample } \\
\hline & All & No ESRD & ESRD & All & No ESRD & ESRD \\
\hline \multicolumn{7}{|l|}{ Reason for visit } \\
\hline General Symptoms & $\begin{array}{l}8187 \\
(19.1)\end{array}$ & $\begin{array}{l}8069 \\
(19.0)\end{array}$ & $\begin{array}{l}118 \\
(32.2)\end{array}$ & $\begin{array}{l}53,664,580 \\
(19.3)\end{array}$ & $\begin{array}{l}52,934,900 \\
(19.2)\end{array}$ & $\begin{array}{l}729,680 \\
(33.7)\end{array}$ \\
\hline Symptoms Referable to Psychological and Mental Disorders & $1700(4.0)$ & $1687(4.0)$ & $13(3.5)$ & $9,426,523(3.4)$ & $9,331,220(3.4)$ & $95,303(4.4)$ \\
\hline Symptoms Referable to the Nervous System & $3304(7.7)$ & $3279(7.7)$ & $25(6.8)$ & $20,833,741(7.5)$ & $20,708,936(7.5)$ & $124,805(5.8)$ \\
\hline $\begin{array}{l}\text { Symptoms Referable to the Cardiovascular and Lymphatic } \\
\text { Systems }\end{array}$ & $889(2.1)$ & $877(2.1)$ & $12(3.3)$ & $5,993,917(2.2)$ & $5,914,527(2.1)$ & $79,390(3.7)$ \\
\hline Symptoms Referable to the Eyes and Ears & $848(2.0)$ & $847(2.0)$ & $1(0.3)$ & $5,778,778(2.1)$ & $5,772,695(2.1)$ & $6083(0.3)$ \\
\hline Symptoms Referable to the Respiratory System & $4198(9.8)$ & $4135(9.8)$ & $63(17.2)$ & $\begin{array}{l}27,856,021 \\
(10.0)\end{array}$ & $\begin{array}{l}27,508,840 \\
(10.0)\end{array}$ & $\begin{array}{l}347,181 \\
(16.0)\end{array}$ \\
\hline Symptoms Referable to the Digestive System & $\begin{array}{l}6807 \\
(15.9)\end{array}$ & $\begin{array}{l}6758 \\
(15.9)\end{array}$ & $49(13.4)$ & $\begin{array}{l}46,038,272 \\
(16.5)\end{array}$ & $\begin{array}{l}45,725,454 \\
(16.6)\end{array}$ & $\begin{array}{l}312,819 \\
(14.4)\end{array}$ \\
\hline Symptoms Referable to the Genitourinary System & $2477(5.8)$ & $2462(5.8)$ & $15(4.1)$ & $14,984,361(5.4)$ & $14,913,890(5.4)$ & $70,470(3.3)$ \\
\hline Symptoms Referable to the Skin, Nails, and Hair & $1333(3.1)$ & $1328(3.1)$ & $5(1.4)$ & $8,716,118(3.1)$ & $8,690,203(3.1)$ & $25,915(1.2)$ \\
\hline Symptoms Referable to the Musculoskeletal System & $\begin{array}{l}6519 \\
(15.2)\end{array}$ & $\begin{array}{l}6493 \\
(15.3)\end{array}$ & $26(7.1)$ & $\begin{array}{l}42,820,579 \\
(15.4)\end{array}$ & $\begin{array}{l}42,682,302 \\
(15.5)\end{array}$ & $138,277(6.4)$ \\
\hline Other & $\begin{array}{l}6501 \\
(15.2)\end{array}$ & $\begin{array}{l}6461 \\
(15.2)\end{array}$ & $40(10.9)$ & $\begin{array}{l}42,147,135 \\
(15.1)\end{array}$ & $\begin{array}{l}41,908,983 \\
(15.2)\end{array}$ & $\begin{array}{l}238,152 \\
(11.0)\end{array}$ \\
\hline
\end{tabular}

1.53 times more likely to be ESRD patients (95\% CI: 1.00-2.34). Compared to ED patients with private insurance, those with Medicare and Medicaid or CHIP were 4.23 and 2.05 times more likely to have ESRD (95\% CI: 2.89-6.19, CI: 1.35-3.12, respectively).

Regarding vital signs, compared to patients with a DBP of 60-80, ED patients with DBP lower than 60 were 1.92 times to be ESRD patients (95\% CI: 1.442.56). Compared to patients who arrived at the ED by other means, patients who arrived by ambulance were 1.58 times more likely to have ESRD (95\% CI: 1.242.01). Meanwhile, ED patients who presented with an adverse effect of medical/surgical treatment were 6.58 times more likely to have ESRD than those presenting with injury or trauma (95\% CI: 4.07-10.64).

\section{Discussion}

ESRD is a complex clinical condition caused by chronic kidney disease, high blood pressure, and others, and the incidence of ESRD increases sharply with age in both sexes [13]. ESRD patients need special and professional health care in both emergency and non-emergency cases. Additionally, diabetes and hypertension account for more than $50 \%$ of cases of ESRD, and care of these patients increasingly depends on primary care physicians [14]. To our knowledge, this study is a representative large-scale study describing national characteristics of ED visits by ESRD patients. A thoughtful study by Lovasik et al. [15] examined the use of the ED among ESRD patients with Medicare. However, the population of their study was limited to ED patients with Medicare only, and the analysis of the study was around the characteristics of hospitalization. Our study focuses on all ED adult patient visits between 2014 and 2016 in the United States, and the study conclusions were drawn from a comparison of ED visits by patients with ESRD and nonESRD status. In addition, our study also provides medical resource utilization information related to ED visits by ESRD patients, such as use the of blood tests and medical imaging in this population. This more extensive characterization helps generate nationally-representative results about ED visits by ESRD patients. Another ED utilization analysis by Ronksley et al. [16] was national in scope but explored ED use among patients with CKD rather than ESRD, whereas the focus of the present study is ESRD.

From 2014 to 2016, 2,168,075 ESRD patients visited the ED in total, and the number of annual visits by those patients has increased stably. Demographic factors were associated with the prevalence of ESRD in ED patients. One important demographic factor is age. Our study analysis suggests that compared to patients who visit the ED and do not have ESRD, ESRD patients who visit the ED are more likely to be senior patients. This increased likelihood of older age makes sense within the context of other trends. For example, nearly half of incident dialysis patients in the United States annually are senior citizens [17]. Age alone increases the risk of mortality in ESRD patients [18]. And, in addition to being an independent risk factor for increased mortality in patients with ESRD, increased age carries further risk because aging is also associated with cardiovascular disease. The 
Table 3 Proportion of emergency severity index, hospital admission, ICU admission, medical resources utilization, stratified by ESRD, NHAMCS 2014-2016

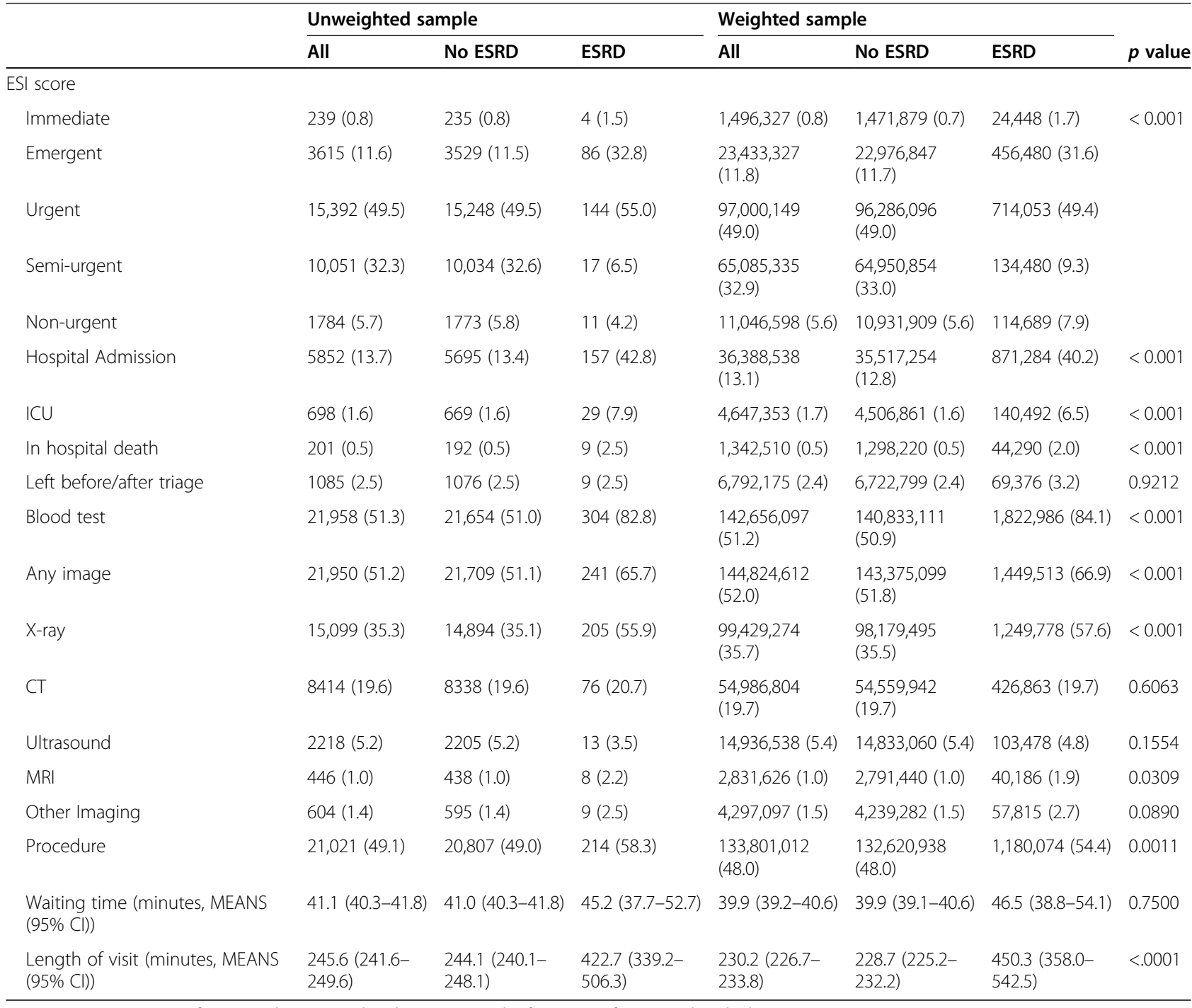

Notes: Waiting time: time from arrival to seeing the physician. Length of visit: time from arrival to discharge

cardiovascular mortality rate in ESRD patients is 10 to 20 times higher than that rate in the general population [19]. Therefore, clinical care of cardiovascular disease among these older ED patients with ESRD is necessary. As a result of these increased risks associated with age, we can expect that these older ESRD patients may require more extensive use of ED resources.

Another important demographic factor is gender. Our study suggests that compared to patients who visit the ED and do not have ESRD, ESRD patients who visit the ED are more likely to be male. This same gender difference in ESRD patients has been documented in the field of nephrology. For example, a nationwide survey of ESRD by the Japanese Society for Dialysis Therapy revealed a higher incidence and prevalence of ESRD in men, according to their research on gender differences in chronic kidney disease [20]. Some studies have found that women with ESRD have a reduced mortality risk [21], while others have found that this mortality risk advantage is diminished when assessing the risk of mortality in men and women who are on hemodialysis [22]. Further research into the complex interactions between gender and ESRD status is needed in order to understand how the increased proportion of male ESRD patients in the ED can translate into adjustments to clinical decision making in the ED.

Our study suggests that the ED visits prevalence among ESRD patients is significant higher in the South. Previous studies have assessed for geographic differences in ESRD incidence in the U.S. Rosansky et al. (1990) [23] found that ESRD treatment rates varied regionally across the U.S. after adjusting for race, sex, and age differences 
Table 4 Odds ratio of emergency severity index, hospital admission, ICU admission, medical resources utilization for ESRD vs. nonESRD patients, NHAMCS 2014-2016

\begin{tabular}{|c|c|c|c|c|}
\hline & \multirow{2}{*}{$\begin{array}{l}\text { Crude odds } \\
\text { ratio }\end{array}$} & \multicolumn{3}{|l|}{ Adjusted for } \\
\hline & & Demographics & + Social economic & + Visiting \& Clinical \\
\hline ESI Score: Immediate or Emergent vs. Semi- or Non-Urgent & $10.07(6.58-15.41)$ & $6.98(4.53-10.74)$ & $6.74(4.37-10.38)$ & $4.72(3.00-7.41)$ \\
\hline ESI Score: Urgent vs. Semi- or Non-Urgent & $3.98(2.65-5.96)$ & $3.33(2.22-5.01)$ & $3.24(2.15-4.87)$ & $2.46(1.62-3.74)$ \\
\hline Hospital Admission & $4.83(3.92-5.95)$ & $3.32(2.67-4.13)$ & $3.30(2.65-4.11)$ & $2.70(2.13-3.41)$ \\
\hline ICU & $5.36(3.64-7.90)$ & $3.25(2.20-4.82)$ & $3.07(2.06-4.58)$ & $2.21(1.45-3.38)$ \\
\hline Death & $5.54(2.81-10.89)$ & $3.03(1.53-6.01)$ & $2.65(1.33-5.30)$ & $1.64(0.76-3.55)$ \\
\hline Left & $0.97(0.50-1.88)$ & $1.23(0.63-2.40)$ & $1.08(0.55-2.11)$ & $0.93(0.47-1.82)$ \\
\hline Blood test & $4.64(3.53-6.09)$ & $3.60(2.73-4.74)$ & $3.41(2.59-4.49)$ & $2.54(1.89-3.40)$ \\
\hline Any imaging & $1.83(1.47-2.27)$ & $1.36(1.09-1.70)$ & $1.36(1.09-1.70)$ & $1.37(1.09-1.72)$ \\
\hline X-ray & $2.34(1.90-2.88)$ & $1.73(1.40-2.14)$ & $1.69(1.36-2.09)$ & $1.79(1.43-2.24)$ \\
\hline$C T$ & $1.07(0.83-1.38)$ & $0.80(0.62-1.03)$ & $0.81(0.63-1.05)$ & $0.80(0.61-1.05)$ \\
\hline Ultrasound & $0.67(0.39-1.17)$ & $0.86(0.49-1.51)$ & $0.88(0.50-1.55)$ & $0.84(0.47-1.48)$ \\
\hline MRI & $2.14(1.06-4.34)$ & $1.58(0.78-3.22)$ & $1.66(0.81-3.39)$ & $1.92(0.93-4.00)$ \\
\hline Procedure & $1.33(1.08-1.63)$ & $1.24(1.01-1.52)$ & $1.24(1.01-1.52)$ & $1.20(0.97-1.47)$ \\
\hline
\end{tabular}

Note: ${ }^{*}+$ Demographics include: gender, age group, race/ethnicity; +Social economic: residence type, insurance type, census region; + Visiting \& Clinical: year, week of day, arrive by ambulance, seen within last $72 \mathrm{~h}$, pain level, temperature, heart rate, dialytic blood pressure, injury status, reason for visit

with very high rates in the southwestern states. Similarly, Foxman et al. (1991) [24], found regional variation across U.S. states with the highest ESRD incidence in the Southwest as well as the Southeast. Tanner et al. (2013) [25] focused on geographic variation in the prevalence of CKD and found that differences in CKD prevalence did not explain geographic variation in ESRD prevalence.

Another important difference revealed in the data is the differences in presenting vital signs between ESRD and non-ESRD patients. Patients with ESRD were more likely to have reduced blood pressure than were patients without ESRD. These alterations of vital signs were related to the adverse effect of medical/surgical treatment, which was the most likely reason for ED visits by ESRD patients. Presentation with alterations in vital signs may be related to outcomes such as increased return visits to the ED, increased rates of readmission, and increased need for higher level of care [26].

Finally, our analysis reveals several other indicators that patients of ESRD may be more complex and higher acuity than other patients. For example, in this study, we found that ED visits by ESRD patients were 1.5 times more likely to be from nursing homes than from a private residence, and that these patients are also more likely to be delivered by ambulance rather than by other means. This is consistent with previous findings that show that receiving hemodialysis in the post-dialysis initiation period was a high-risk time for falls among older adults [27].

Additionally, compared to non-ESRD patients, those with ESRD had higher rates of hospital and ICU admission. The higher rate of revisiting the ED as well as the higher rate of hospital admission in ESRD patients can be associated with higher severity of the condition, poor outcomes of previous treatments, and high costs. Many previous studies have similar findings. For example, the U.S. Renal Data System reported that an overall rehospitalization rate for patients with ESRD was $34 \%$ within 30 days of discharge [28].

Understanding the above characteristics of ED visits by ESRD patients may help the clinicians understand these patients who are at high risk for ED visit, hospital admission, and other health outcomes, as well as the need for increased medical resource use. As a result, clinicians can aim to improve the efficiency of clinical care and reduce the high rates of hospital admission, which in turn would not only benefit ESRD patients but also benefit hospitals in terms of better resource allocation and better financial allocation.

\section{Limitations}

In the patient histories documented in the NHAMCSED data, patients are coded as either having or not having ESRD status, but information such as duration and treatment history were not tracked in the dataset. This information would help to better predict ESRD status among ED patients. As Iseki noted, ESRD is not a specific disease entity, but rather provides a framework for the consideration of treatment options [13]. Understanding the relationship between ESRD and other chronic diseases would help to determine risk factors for utilizing ED resources for ESRD patients. Another limitation 
is that the dataset did not provide information about patients' other health conditions.

\section{Conclusions}

This study enhanced the understanding of clinical characteristics of ED utilization in patients with ESRD. The study describes the characteristics of ESRD patients who visit the ED on a national scale. We found that there are gender, age, and racial/ethnic differences between ED patients with and without ESRD. ESRD patients are also more likely to present with alterations in vitals signs. Also, patients with ESRD are more likely to return to the ED, more likely to visit the ED due to complications of therapy, more likely to reside in a nursing home, and more likely to arrive by ambulance compared to nonESRD patients. The above findings suggest that patients with ESRD have a higher demands for utilizing ED care and resources.

\section{Abbreviations \\ aOR: Adjusted odds ratio; Cl: Confidential interval; ED: Emergency department; NHAMCS-ED: National Hospital Ambulatory Medical Care Survey ED Subfile; ESI: Emergency severity index; ICU: intensive care unit; $\mathrm{CT}$ : Computed tomography; MRI: Magnetic resonance imaging; ESRD: End- stage renal disease}

\section{Supplementary Information}

The online version contains supplementary material available at https://doi. org/10.1186/s12873-021-00420-8.

Additional file 1: Supplement Table 1. Association between ED visiting with ESRD and patient visiting characteristics, NHAMCS 20142016. Note: the adjusted OR was from a logistic regression including all variables in the table.

\section{Acknowledgements}

None.

\section{Authors' contributions}

$X Z$ had full access to all the data in the study and take responsibility for the integrity of the data and the accuracy of the data analysis. Concept and design: JP, XZ. Acquisition, analysis, or interpretation of data: All authors. Drafting of the manuscript: NW, JP, and YA. Critical revision of the manuscript for important intellectual content: HF, JZ, AP, XZ. Statistical analysis: $X Z$, JP. Obtained funding: $X Z$, JP. Administrative, technical, or material support: NW, XZ. The author(s) read and approved the final manuscript.

\section{Funding}

This work was supported by the Sichuan Provincial Innovation Project for Young Investigators in Medical Research (No. Q14050). This study was also supported by Michigan Institute for Clinical and Health Research (MICHR No. UL1TR002240). No funding bodies had any role in study design, data collection and analysis, decision to publish, or preparation of the manuscript.

\section{Availability of data and materials}

The NHAMCS-ED dataset can be accessed through the website of the US Centers for Disease Control and Prevention (CDC) (https://www.cdc.gov/ nchs/ahcd/index.htm). The detailed explanation of the survey data for each year and the code book can be found here: https://ftp.cdc.gov/pub/Health_Statistics/NCHS/dataset_documentation/ nhamcs/

\section{Declarations}

Ethics approval and consent to participate

This study was a secondary analysis of a public database and did not require ethical approval.

\section{Consent for publication}

Not applicable.

\section{Competing interests}

The authors declare that they have no competing interests. The funders/ sponsors had no role in the design and conduct of the study; collection, management, analysis, and interpretation of the data; preparation, review, or approval of the manuscript; and decision to submit the manuscript for publication.

\section{Author details}

${ }^{1}$ College of Literature, Science, and the Arts, University of Michigan, Ann Arbor, USA. ${ }^{2}$ Sichuan Cancer Hospital \& Institute, Sichuan Cancer Center, School of Medicine, University of Electronic Science and Technology of China, Chengdu, China. ${ }^{3}$ Department of Epidemiology and Biostatistics, West China School of Public Health and West China Fourth Hospital, Sichuan University, Chengdu, China. ${ }^{4}$ Department of Preventive Medicine, North Sichuan Medical College, Nanchong, China. ${ }^{5}$ Department of Systems, Populations, and Leadership, University of Michigan School of Nursing, Ann Arbor, MI 48109, USA. ${ }^{6}$ MRC Integrative Epidemiology Unit, University of Bristol, Bristol, UK. ${ }^{7}$ NIHR Bristol Biomedical Research Centre, University of Bristol, Bristol, UK. ${ }^{8}$ Population Health Sciences, Bristol Medical School, University of Bristol, Bristol, UK.

Received: 31 August 2020 Accepted: 23 February 2021

Published online: 02 March 2021

\section{References}

1. Control CfD, Prevention. Chronic kidney disease in the United States, 2019. Atlanta: US Department of Health and Human Services, Centers for Disease; 2019

2. Chronic Kidney Basics. https://www.cdc.gov/kidneydisease/basics.html Accessed 2 Feb 2021.

3. Saran R, Robinson B, Abbott KC, Bragg-Gresham J, Chen X, Gipson D, Gu H, Hirth RA, Hutton D, Jin Y. US renal data system 2019 annual data report: epidemiology of kidney disease in the United States. Am J Kidney Dis. 2020; 75(1S1):A6.

4. McCullough KP, Morgenstern H, Saran R, Herman WH, Robinson BM Projecting ESRD incidence and prevalence in the United States through 2030. J Am Soc Nephrol. 2019:30(1):127-35.

5. London R, Solis A, Goldberg GA, Wade S, Ryu S. Health care resource utilization and the impact of anemia management in patients with chronic kidney disease. Am J Kidney Dis. 2002;40(3):539-48.

6. Hakim RM, Collins AJ. Reducing avoidable rehospitalization in ESRD: a shared accountability. Am Soc Nephrol. 2014.

7. Jencks SF, Williams MV, Coleman EA. Rehospitalizations among patients in the Medicare fee-for-service program. N Engl J Med. 2009;360(14):1418-28

8. Ward A, Alvarez P, Vo L, Martin S. Direct medical costs of complications of diabetes in the United States: estimates for event-year and annual state costs (USD 2012). J Med Econ. 2014;17(3):176-83.

9. van Nooten FE, Green J, Brown R, Finkelstein FO, Wish J. Burden of illness for patients with non-dialysis chronic kidney disease and anemia in the United States: review of the literature. J Med Econ. 2010:13(2):241-56.

10. Long B, Koyfman A, Lee CM. Emergency medicine evaluation and management of the end stage renal disease patient. Am J Emerg Med. 2017;35(12):1946-55

11. Maldonado T, Avner JR. Triage of the pediatric patient in the emergency department: are we all in agreement? Pediatrics. 2004;114(2):356-60.

12. Zhang X, Kim J, Patzer RE, Pitts SR, Patzer A, Schrager JD. Prediction of emergency department hospital admission based on natural language processing and neural networks. Methods Inf Med. 2017;56(05):377-89.

13. Iseki K, Iseki C, Ikemiya Y, Fukiyama K. Risk of developing end-stage renal disease in a cohort of mass screening. Kidney Int. 1996;49(3):800-5.

14. Bello AK, Nwankwo E, El Nahas AM. Prevention of chronic kidney disease: a global challenge. Kidney Int. 2005;68:S11-7. 
15. Lovasik BP, Zhang R, Hockenberry JM, Schrager JD, Pastan SO, Mohan S, Patzer RE. Emergency department use and hospital admissions among patients with end-stage renal disease in the United States. JAMA Intern Med. 2016;176(10):1563-5.

16. Ronksley PE, Tonelli M, Manns BJ, Weaver RG, Thomas CM, MacRae JM, Ravani P, Quinn RR, James MT, Lewanczuk R. Emergency department use among patients with CKD: a population-based analysis. Clin J Am Soc Nephrol. 2017;12(2):304-14.

17. Bethesda M. US renal data system, USRDS annual data report. Atlas of chronic kidney disease and end-stage renal disease in the United States National Institutes of Health National Institute of Diabetes and Digestive and Kidney Diseases. 2011.

18. Babayev R, Whaley-Connell A, Kshirsagar A, Klemmer P, Navaneethan S, Chen S-C, Li S, McCullough PA, Bakris G, Bomback A. Association of race and body mass index with ESRD and mortality in CKD stages 3-4: results from the Kidney Early Evaluation Program (KEEP). Am J Kidney Dis. 2013; 61(3):404-12.

19. Levey AS, Beto JA, Coronado BE, Eknoyan G, Foley RN, Kasiske BL, Klag MJ, Mailloux LU, Manske CL, Meyer KB. Controlling the epidemic of cardiovascular disease in chronic renal disease: what do we know? What do we need to learn? Where do we go from here? National Kidney Foundation Task Force on Cardiovascular Disease. Am J Kidney Dis. 1998:32(5):853.

20. Iseki K. Gender differences in chronic kidney disease. Kidney Int. 2008;74(4): 415-7.

21. Villar E, Remontet L, Labeeuw M, Ecochard R. Effect of age, gender, and diabetes on excess death in end-stage renal failure. J Am Soc Nephrol. 2007;18(7):2125-34.

22. Hecking M, Bieber BA, Ethier J, Kautzky-Willer A, Sunder-Plassmann G, Säemann MD, Ramirez SPB, Gillespie BW, Pisoni RL, Robinson BM. Sexspecific differences in hemodialysis prevalence and practices and the maleto-female mortality rate: the Dialysis Outcomes and Practice Patterns Study (DOPPS). PLoS Med. 2014;11(10):e1001750.

23. Rosansky SJ, Huntsberger TL, Jackson K, Eggers P. Comparative incidence rates of end-stage renal disease treatment by state. Am J Nephrol. 1990; 10(3):198-204

24. Foxman B, Moulton LH, Wolfe RA, Guire KE, Port FK, Hawthorne VM. Geographic variation in the incidence of treated end-stage renal disease. J Am Soc Nephrol. 1991;2(6):1144.

25. Tanner RM, Gutiérrez OM, Judd S, McClellan W, Bowling CB, Bradbury BD, Safford MM, Cushman M, Warnock D, Muntner P. Geographic variation in CKD prevalence and ESRD incidence in the United States: results from the reasons for geographic and racial differences in stroke (REGARDS) study. Am J Kidney Dis. 2013;61(3):395-403.

26. Hodgson NR, Poterack KA, Mi L, Traub SJ. Association of vital signs and process outcomes in emergency department patients. West J Emerg Med. 2019;20(3):433.

27. Plantinga $L C$, Patzer RE, Franch HA, Bowling CB. Serious fall injuries before and after initiation of hemodialysis among older ESRD patients in the United States: a retrospective cohort study. Am J Kidney Dis. 2017;70(1):7683.

28. System URD. USRDS 2013 annual data report: atlas of chronic kidney disease and end-stage renal disease in the United States. In: National Institutes of Health, National Institute of Diabetes and Digestive ...; 2013.

\section{Publisher's Note}

Springer Nature remains neutral with regard to jurisdictional claims in published maps and institutional affiliations.

Ready to submit your research? Choose BMC and benefit from:
- fast, convenient online submission
- thorough peer review by experienced researchers in your field
- rapid publication on acceptance
- support for research data, including large and complex data types
- gold Open Access which fosters wider collaboration and increased citations
- maximum visibility for your research: over 100M website views per year
At BMC, research is always in progress.
Learn more biomedcentral.com/submissions

